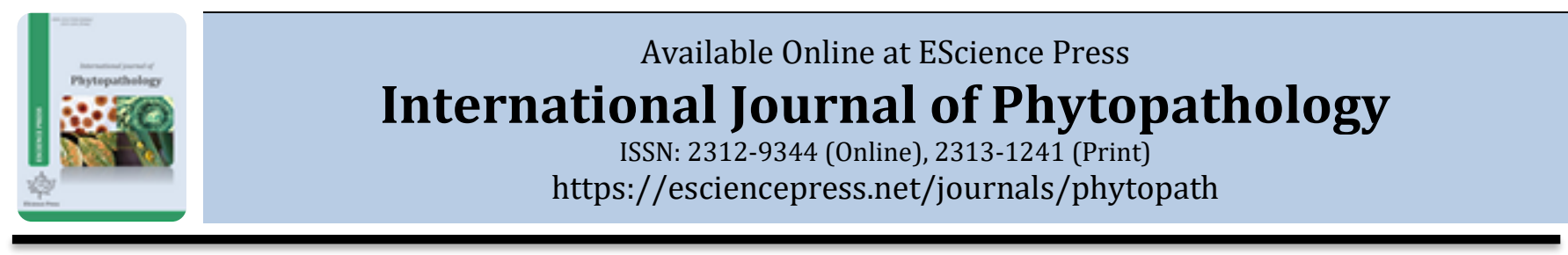

\title{
FIRST REPORT OF PHYTOPHTHORA CAPSICI INFECTION ON BELL PEPPERS (CAPSICUM ANNUUM L.) FROM PUNJAB, PAKISTAN
}

aSajjad Hyder*, aM. Inam-ul-Haq, aRaees Ahmed, aAmjad S. Gondal, bNida Fatima, 'Abdul Hanan, dYoufu F. Zhao

${ }^{a}$ Department of Plant Pathology, PMAS-Arid Agriculture University Rawalpindi, Pakistan.

${ }^{b}$ Institute of Soil Science and Soil Water Conservation, PMAS-Arid Agriculture University Rawalpindi, Pakistan.

c Department of Botany, Ghazi University, Dera Ghazi Khan, Pakistan.

${ }^{d}$ Department of Crop Sciences, University of Illinois at Urbana Champaign, Illinois, USA.

*Corresponding Author Email: sajjad1614@gmail.com

\section{A B S T R A C T}

Bell pepper (Capsicum annuum L.) is one of the extensively cultivated vegetable crop in Punjab, Pakistan. During two years of field surveys, February-November 2016-17, damping off and blight symptoms were observed. Average seedling mortality was recorded as $18.7 \%$ while yield loss due to blight was estimated 32 to $41 \%$ at mature stages. Maximum blight infection was recorded from the areas frequently flooded with canal irrigation system. At early stages, lesions were noticed on stem portions at soil line level while at crop maturity stages blight symptoms were noted. Leaves were blanched and wilted while fruits were covered with white mold. Masses of sporangia were evident on and inside the infected fruits under humid conditions. A total of twelve isolates were recovered from infected root, stem and fruit portions on rye agar media (Caten and Jinks, 1968) incubated at $25^{\circ} \mathrm{C}$ under fluorescent light. Papillated sporangia were averaged $42 \pm 2.6 \times 27 \pm 1.7 \mu \mathrm{m}$ in size (range $27-52 \times 23-36 \mu \mathrm{m}$ ). Oospores were produced on $20 \%$ V8 agar and were spherical $22 \pm 1.4 \mu \mathrm{m}$ in diameter (range 14 to $27 \mu \mathrm{m}$ ) while average pedicels length was recorded as $58 \pm 12.5 \mu \mathrm{m}$ (range 13 to $120 \mu \mathrm{m}$ ). These observations were similar to those described for P. capsici (Cocoa, 1988). DNA was extracted using Cetyl Trimethylammonium Bromide (CTAB) method and the internal transcribed spacer regions (ITS1 and ITS2) were amplified by polymerase chain reaction (White et al., 1990). The amplicons were purified and sequenced in both directions (GenBank Accession No. MF322868 and MF322869). BLAST analysis revealed these isolates showed 99\% identity with ITS sequences of Phytophthora capsici (KM369964 and KU518782). Pathogenicity assay was performed on healthy bell pepper seedlings with five repeats. Soil was flooded with $20 \mathrm{ml}$ sporangial suspension $\left(1 \times 10^{3}\right.$ sporangia/ml) in pots containing seedlings while $5 \mathrm{ml}$ suspension was sprayed until run off on mature plants (Hyder et al., 2018). A set of uninoculated seedlings was used as control. Pots were kept in dew chamber for 10-20 days at $25 \pm 2{ }^{\circ}$ C. Seedling mortality was observed five days after inoculation while at later stage plants develop brown-to-black stem lesions with white mycelial growth on leaves. These symptoms were identical to the P. capsici infections in field. Consistent re-isolations of $P$. capsici confirm its association with the disease. To our knowledge, this is the first report of Phytophthora blight on bell pepper from Pakistan.

\section{REFERENCES}

Caten, C. E. and J. L. Jinks. 1968. Spontaneous variability of single isolates of Phytophthora infestans. I. cultural variation. Canadian Journal of Botany, 46: 329-48.

Cocoa, P. A. 1988. 10th international cocoa research conferenceCocoa Producers' Alliance. Santo Domingo, Dominican Republic.

Hyder, S., M. Inam-ul-Haq, M. Ashfaq, A. Ahmad, A. S. Gondal and M. Iqbal. 2018. First Report of Pythium myriotylum D., Causing Damping Off and Root Rot in Chili Pepper (Capsicum annum L.) from Punjab, Pakistan. Plant Disease, 102: 687.

White, T. J., T. Bruns, S. Lee and J. Taylor. 1990. Amplification and direct sequencing of fungal ribosomal RNA genes for phylogenetics PCR Protocols. Elsevier. pp. 315-22.

\footnotetext{
Running Title: Phytophthora capsici causing damping off and blight of bell pepper
} 